\title{
A Seamless Transfer Algorithm Based on Frequency Detection with Feedforward Control Method in Distributed Generation System
}

\author{
Kiryong Kim*, Dongsul Shin ${ }^{*}$ Jaecheol Lee ${ }^{*}$ Jong-Pil Lee ${ }^{* *}$, Dong-Wook Yoo ${ }^{* *}$, and Hee-Je Kim ${ }^{\dagger}$ \\ ${ }^{*}$ Dept. of Electrical Eng., Pusan National University, Busan, Korea \\ ${ }^{* *}$ Power Conversion Research Center, HVDC Research Division, KERI, Changwon, Korea
}

\begin{abstract}
This paper proposes a control strategy based on the frequency detection method, comprising a current control and a feed-forward voltage control loop, is proposed for grid-interactive power conditioning systems (PCS). For continuous provision of power to critical loads, PCS should be able to check grid outages instantaneously. Hence, proposed in the present paper are a frequency detection method for detecting abnormal grid conditions and a controller, which consists of a current controller and a feedforward voltage controller, for different operation modes. The frequency detection method can detect abnormal grid conditions accurately and quickly. The controller which has current and voltage control loops rapidly helps in load voltage regulation when grid fault occurs by changing reference and control modes. The proposed seamless transfer control strategy is confirmed by experimental results.
\end{abstract}

Key words: Feedforward control, Power conditioning system, Seamless transfer

\section{INTRODUCTION}

Electrical energy consumption has increased with the development of power technology. Much of electrical energy is mainly supplied by thermal power and nuclear power, that is, by centralized generation.

However, these forms of energy are becoming a source of environmental pollution [1], [12]. For reducing environmental problems, renewable energy has been recognized as a major alternative to fossil fuels. Given these concerns (i.e., environmental pollution and the increase in demands for energy), distributed generation (DG), which is based on distributed resources (DR) such as the photovoltaic materials, wind turbines, etc., has gained attention [5]. However, the output power of DRs is unstable; thus, an energy storage system, particularly, a battery energy storage system (BESS), is

Manuscript received Dec. 4, 2014; accepted Mar. 13, 2015

Recommended for publication by Associate Editor Kyo-Beum Lee.

${ }^{\dagger}$ Corresponding Author: heeje@pusan.ac.kr

Tel: +82-51-510-2770, Mobile: +82-10-2295-0613, Pusan Nat'l Univ.

*Dept. of Electrical Eng., Pusan National University, Korea

${ }^{* *}$ Power Conversion Research Center, HVDC Research Division, KERI, Korea required to support DRs [2]. The DG system with BESS has promoted the development of a new grid paradigm - the micro-grid — which plays a leading role in the smart-grid of the future [3]. Hence, the BESS and power conditioning systems (PCS) play important roles in maintaining demand/supply balance and power quality. According to the concept of the future grid, each power system must have multiple functions.

For example, the functions of the BESS can be combined with the functions of an uninterrupted power supply to continuously provide stable power to the loads of a system, reducing transient time when a power outage occurs, which may then reduce size and costs.

For the aforementioned function to be implemented by the PCS, it should first provide a seamless transfer control method. Generally, two operation modes, depending on grid conditions, are needed for seamless transfer control. One operation mode is a grid-connected (GC) mode and the other is a stand-alone (SA) mode, that is, for normal grid conditions and for abnormal grid conditions, respectively. Under each mode, the power components, current and voltage, are controlled.

If only one control (i.e., current control or voltage control) is provided and operation mode is suddenly changed, a voltage or 
current abnormal transient phenomenon will occur, imposing negative effects on critical loads and the PCS. Hence, seamless transfer control is necessary.

Several types of seamless transfer control strategies are proposed in [6]-[10]. The main issues addressed by these control strategies are clearing time reduction and continuous maintenance of load voltage when the PCS is operating in SA mode. In [6]-[8], the indirect current control method is utilized. In the case where grid current is controlled by regulating capacitor voltage, load voltage quality can be improved during the transition between operation modes because the capacitor voltage control loop can always regulate load voltage. However, the instantaneous values of power components (e.g., voltage and current) are difficult to calculate. A unified control provides a method wherein islanding need not be quickly and accurately detected, which is achieved by controlling the inverter output current while the load voltage is being monitored. However, this control method maintains higher voltages than the normal grid voltage reference in the SA mode [9]. The control method in [10] can detect voltage grid conditions (e.g., grid over voltage, voltage swell) and can quickly change operation mode. However, this strategy deals with grid over voltage conditions only; other abnormal grid conditions like under grid voltage and frequency, were not mentioned in the literature.

The detection of grid fault conditions in these control methods are based on voltage conditions. However, this voltage condition-based method is less sensitive than the frequency condition method. As shown in Table. I, the voltage range is divided into four cases, the clearing time under each of which is different. The boundaries of each case have a degree of uncertainty due to voltage fluctuations. Meanwhile, in terms of frequency, only two cases are indicated, both of which have the same clearing time. This indicates a sensitive frequency that can quickly detect abnormal conditions. The quick detection of grid faults, as well as the quick changing of operation modes to reduce transient time, is important. Thus, proposed in this paper is a seamless transfer control with frequency detection using feedforward control method.

A current control with a feedforward voltage control loop is used to reduce the transient time between GC mode and SA mode. In GC mode, or under normal grid conditions, the PCS operates as a voltage-controlled current source. Hence, the PCS injects the current to the grid. In this mode, load and grid voltage are equal because the load voltage is governed by the grid voltage. In the SA mode, or under abnormal grid conditions, load voltage is not equal to grid voltage. Therefore, the PCS quickly maintains a load voltage equal to the grid voltage. The feedforward voltage control loop helps in the rapid regulation and use of load current, which helps reduce transient time.

This paper is organized as follows. In Section II, the three-phase grid interactive PCS topology, which is used

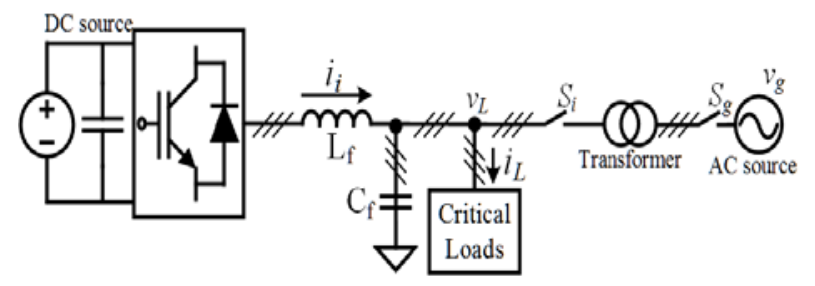

Fig. 1. Three-phase grid interactive PCS topology.

TABLE I

Abnormal Voltage, FreQuency RANGe, AND CleARing Time

\begin{tabular}{c|c}
\hline $\begin{array}{c}\text { Voltage range } \\
\text { of base voltage })\end{array}$ & Clearing time (s) \\
\hline \hline $\mathrm{V}<50$ & 0.16 \\
\hline $50 \leq \mathrm{V}<88$ & 2.00 \\
\hline $110<\mathrm{V}<120$ & 1.00 \\
\hline $120 \leq \mathrm{V}$ & 0.16 \\
\hline \hline Frequency Range (Hz) & Clearing time (s) \\
\hline$f<59.3$ & 0.16 \\
\hline$f>60.5$ & 0.16 \\
\hline
\end{tabular}

generally, is introduced. The proposed seamless transfer control algorithm is described in Section III. In Section IV, results of the experiment, wherein the proposed seamless transfer control method is introduced to each of the critical load condition cases, are presented. Finally, Section V concludes this paper.

\section{SYSTEM DESCRIPTION}

In this paper, proposed for the three-phase grid interactive PCS is a seamless transfer control algorithm for realizing a seamless transfer between the GC and SA modes.

As shown in Fig. 1, the PCS topology consists of a DC source and a three-phase inverter comprising IGBTs and an output LC filter. This output filter is composed of an inductor $\left(\mathrm{L}_{\mathrm{f}}\right)$ and a capacitor $\left(\mathrm{C}_{\mathrm{f}}\right)$. In addition, the output $\mathrm{LC}$ filter is connected to a critical load which consists of parallel RLC, an inverter side switch $\left(S_{i}\right)$, which protects the critical load and the PCS when grid fault occurs, a step-up transformer, and a grid side switch $\left(S_{g}\right)$, which simulates abnormal grid conditions intentionally.

According to IEEE Std. 1547-2003 [4] and Table. I, the PCS checks grid conditions continuously. Grid fault begins when $S_{g}$ is opened. The PCS instantly detects the grid fault signal, commands the $S_{i}$ to open, and changes the PCS operation mode. In other words, when a grid fault occurs, the PCS ceases to energize the grid by disconnecting the $S_{i}$ within a specific clearing time, as derived in Table I, which refers to the total time between when the $S_{g}$ was opened (i.e., at the occurrence of the grid fault) and when PCS opened the $S_{i}$.

\section{Proposed CONTROL AlgORITHM DESCRIPTION}




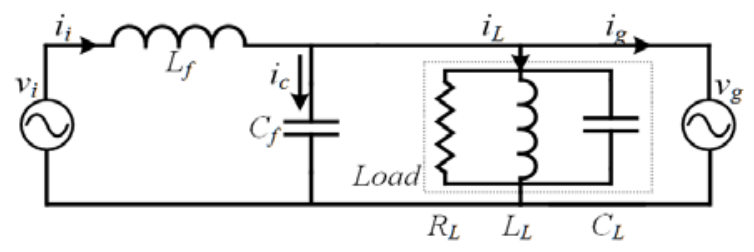

Fig. 2. Equivalent circuit of the PCS in GC mode.

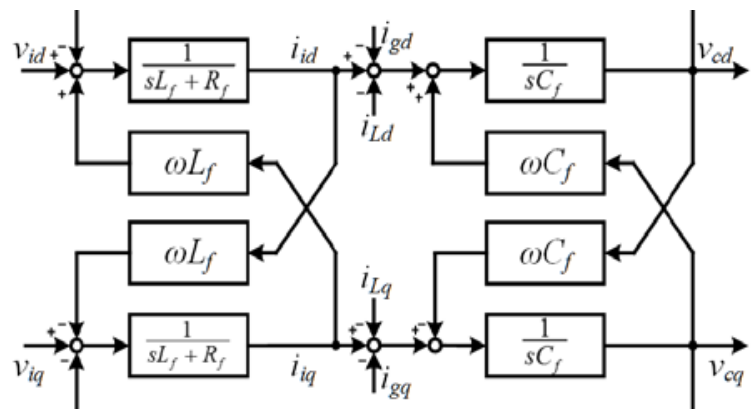

Fig. 3. Model of the PCS power stage.

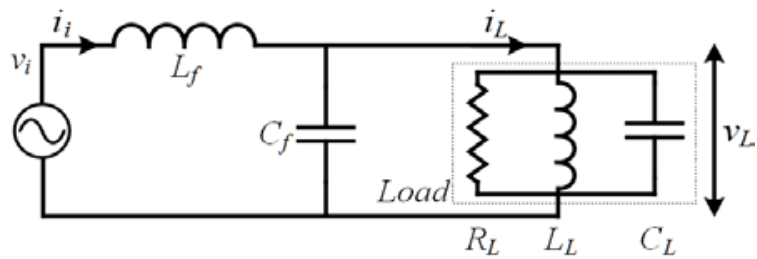

Fig. 4. Equivalent circuit of the PCS in SA mode.

In this paper, we assume that the DC link voltage is constant. Hence, the dynamic performance caused by DC link is not a consideration. Fig. 2 shows the equivalent circuit of the GC mode. In this mode, voltage and current can be derived as in (1) and (2).

$$
\begin{aligned}
& {\left[\begin{array}{l}
v_{i, d} \\
v_{i, q}
\end{array}\right]=L_{f} \frac{d}{d t}\left[\begin{array}{l}
i_{i, d} \\
i_{i, q}
\end{array}\right]+\left[\begin{array}{cc}
0 & -\omega L_{f} \\
\omega L_{f} & 0
\end{array}\right]\left[\begin{array}{l}
i_{i, d} \\
i_{i, q}
\end{array}\right]+R_{f}\left[\begin{array}{l}
i_{i, d} \\
i_{i, q}
\end{array}\right]+\left[\begin{array}{l}
v_{g, d} \\
v_{\mathrm{g}, q}
\end{array}\right]} \\
& {\left[\begin{array}{l}
i_{i, d} \\
i_{i, q}
\end{array}\right]=C_{f} \frac{d}{d t}\left[\begin{array}{l}
v_{c, d} \\
v_{c, q}
\end{array}\right]+\left[\begin{array}{cc}
0 & -\omega C_{f} \\
\omega C_{f} & 0
\end{array}\right]\left[\begin{array}{l}
v_{c, d} \\
v_{c, q}
\end{array}\right]+\left[\begin{array}{l}
i_{L, d} \\
i_{L, q}
\end{array}\right]+\left[\begin{array}{l}
i_{\mathrm{g}, d} \\
i_{\mathrm{g}, q}
\end{array}\right]}
\end{aligned}
$$

where $v_{i, d q}$ is the inverter output voltage in the synchronous reference frame (SRF), $R_{f}$ is the equivalent series resistance (ESR) of filter inductor $\mathrm{L}_{\mathrm{f}}, \mathrm{C}_{\mathrm{f}}$ is the filter capacitor and $\omega$ is the angular frequency of the grid.

Under the GC mode operation, the capacitor voltage is equal to grid voltage. From (1) and (2), the PCS power stage, as shown in Fig. 3, can be expressed. Moreover, load voltage is also equal to grid voltage (i.e., $v_{c, d q}=v_{L, d q}=v_{g, d q}$ ). Meanwhile, in SA mode, the grid is disconnected from the load Fig. 4. This mode can be expressed as in (3).

$$
\left[\begin{array}{c}
v_{\text {id }} \\
v_{\text {iq }}
\end{array}\right]=L_{f} \frac{d}{d t}\left[\begin{array}{l}
i_{i d} \\
i_{i q}
\end{array}\right]+\left[\begin{array}{cc}
0 & -\omega L_{f} \\
\omega L_{f} & 0
\end{array}\right]\left[\begin{array}{l}
i_{\text {id }} \\
i_{i q}
\end{array}\right]+R_{f}\left[\begin{array}{l}
i_{i d} \\
i_{i q}
\end{array}\right]+Z_{\text {load }}\left[\begin{array}{l}
i_{i d} \\
i_{i q}
\end{array}\right] \text { (3) }
$$

where $Z_{\text {load }}=R_{L} / / s L_{L} / / \frac{1}{s C_{L}}$

The PCS operates as a voltage source to provide power to critical loads. In other words, the PCS should continuously maintain load voltage as if the system is connected to the grid.
Inverter output current $i_{i, a b c}$, load current $i_{L, a b c}$, load voltage $v_{L, a b c}$, and grid voltage $v_{g, a b c}$ are sensed. These sensed signals are processed by the digital signal processor (TMS320F28335 Texas Instruments).

For these signal to be controlled, the three-phase signals are changed into SRF signals. Therefore, phase information is required to change the frame. The phase-locked loop (PLL) is used for obtaining phase and frequency information. The most popular phase-detection method available for the three-phase system is the SRF-PLL, which uses an estimated phase to transform a three-phase signal into dq components. $i_{i, d q}, i_{L, d q}$, and $v_{L, d q}$ are the inverter output current, load current, and load voltage of the SRF components, respectively, shown in Fig. 5, which represents the block diagram of the proposed seamless transfer control algorithm.

A detailed description of the control is provided in the following sections.

\section{A. Grid Fault Detection Method}

The frequency detection method is used to compensate for the failure of the abnormal voltage-condition method [12] in addressing other abnormal grid conditions. Frequency detection method can quickly detect grid-fault time. Clearing time is also important in the seamless transfer control system. The system must disconnect at the grid side within the appropriate clearing time, as specified in Table I.

To employ the frequency detection method, we use load voltage to get grid information. When the grid is connected to the load (i.e., in GC mode), load voltage and frequency are governed by the grid. Therefore, load condition is the same as grid condition. However, when the grid is disconnected from the load (i.e., in SA mode), load information is not the same as grid information. Although the PCS quickly regulates load voltage, the load components, voltage or frequency, are changed when the grid is disconnected instantly.

Therefore, load voltage and frequency are suitable bases for decisions regarding the operation mode of the PCS.

\section{B. Reference Calculation}

The output power of the PCS is derived as

$$
\begin{aligned}
P_{i} & =\frac{3}{2}\left(v_{L d} i_{i d}+v_{L q} i_{i q}\right) \\
Q_{i} & =\frac{3}{2}\left(v_{L q} i_{i d}-v_{L d} i_{i q}\right)
\end{aligned}
$$

where $P_{i}$ is the PCS output active power and $Q_{i}$ is the PCS output reactive power respectively.

In GC mode, the current references with regard to the active power and reactive power reference in SRF can be expressed as

$$
\left[\begin{array}{c}
i_{i d}^{*} \\
i_{i q}^{*}
\end{array}\right]=\frac{2}{3} \frac{1}{\left(\mathrm{v}_{L d}^{2}+\mathrm{v}_{L q}^{2}\right)}\left[\begin{array}{cc}
v_{L d} & v_{L q} \\
v_{L q} & -v_{L d}
\end{array}\right]\left[\begin{array}{c}
P_{i}^{*} \\
Q_{i}^{*}
\end{array}\right]
$$

where, $P_{i}^{*}$ and $Q_{i}^{*}$ are the active and reactive 


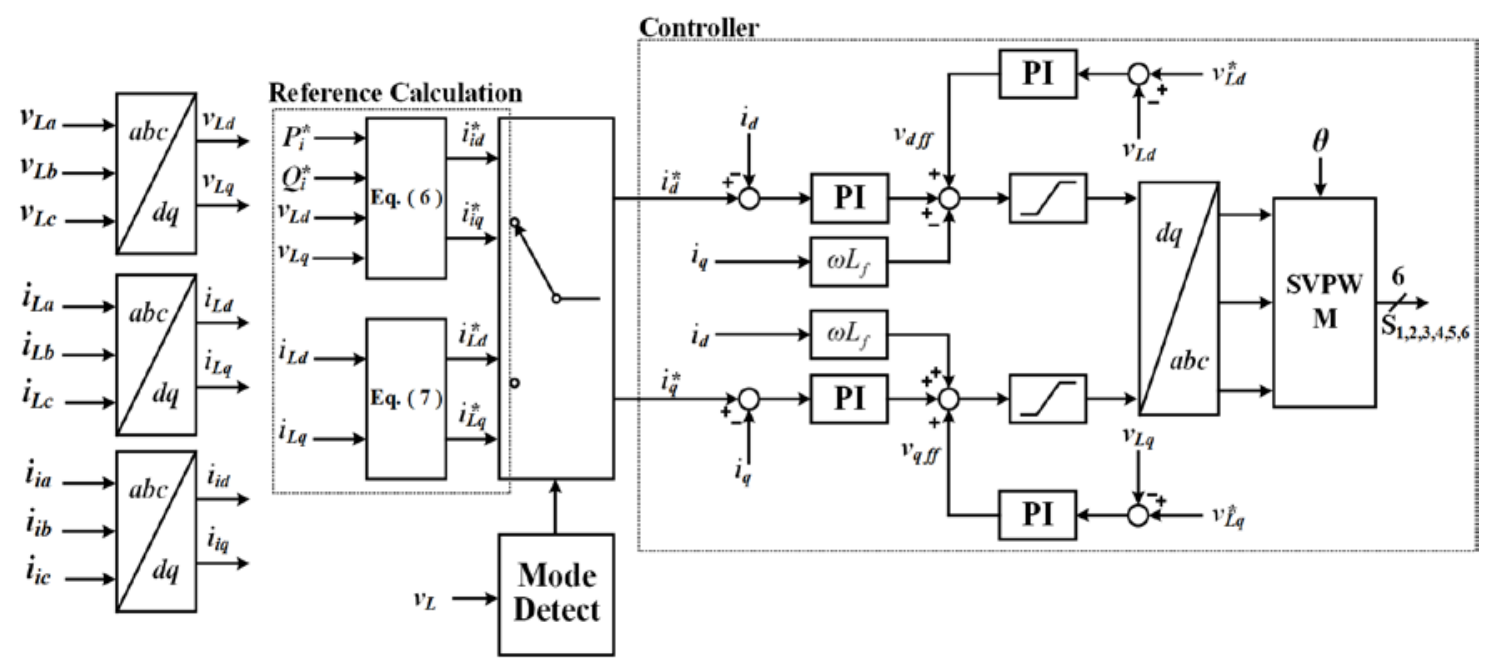

Fig. 5. Proposed control algorithm block diagram.

power of the output reference, respectively, $i_{i d}^{*}$ and $i_{i q}^{*}$ are the output current references along the $d$ - and q-axes, respectively.

In the SA mode, the current references in the $\mathrm{d}-\mathrm{q}$ axis can be expressed as

$$
\left[\begin{array}{l}
i_{i d}^{*} \\
i_{i q}^{*}
\end{array}\right]=\left[\begin{array}{l}
i_{L d} \\
i_{L q}
\end{array}\right]
$$

where $i_{L d}$ is the d-axis and $i_{L q}$ is the q-axis load current respectively.

The current reference in the SA mode is only used as load current to protect the critical load. The load current stays the same regardless of the PCS operation mode. Directly obtaining load current helps reduce calculation time, which can result in decreased transient time.

\section{Proposed Seamless Transfer Control Algorithm}

According to Table I, the PCS determines its operation mode. When the grid is within the normal range, both switches $S_{g}$ and $S_{i}$ are on, and the PCS operates in GC mode. The current reference is determined by (6).

When the grid is beyond the normal range, the $S_{g}$ is opened and the PCS disconnects from the grid by opening the $S_{i}$ and switches operation modes. As the mode is changed, the current reference is also changed. In SA mode, the current reference is determined by (7). Use of the load current directly when grid fault occurs instantly can reduce transient time.

Fig. 6 shows a general voltage control loop with an inner current control loop (i.e., cascade type). The voltage control dynamics is affected by the inner current control loop. Sequential access is needed to obtain the output value. Hence, delay time is produced and system dynamics is affected. In addition, voltage control is difficult under a light-load condition because of the low current value therein.

Therefore, a seamless transfer control that uses a feedforward control method is proposed (Fig. 8). The

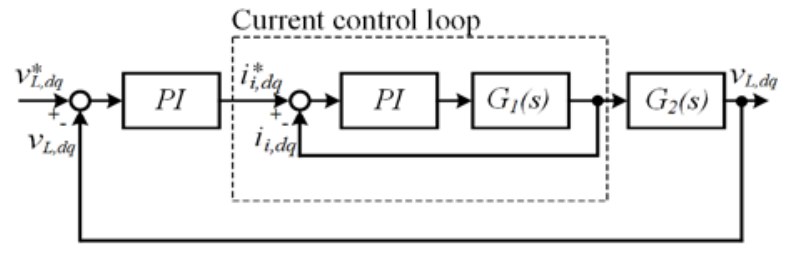

Fig. 6. Conventional voltage control with current control loop.

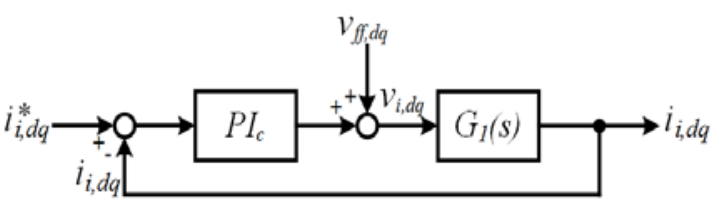

Fig. 7. GC mode control diagram

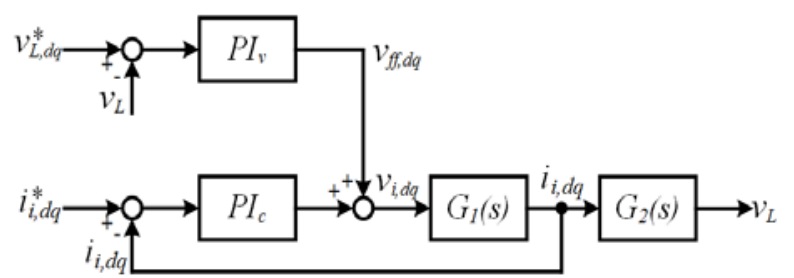

Fig. 8. SA mode control diagram.

feedforward control (i.e., parallel type) helps reduce transient time during operating-mode change. In addition, this control can operate under light-load conditions because the current control therein has minimal effects on the voltage control. Hence, the voltage control loop only addresses the load voltage.

In the GC mode, the controller operates as a voltage-controlled current source because in this mode, the load voltage is equal to the grid voltage (i.e., $v_{L}=v_{g}$ ). The output value of the voltage feedforward control is almost zero, as shown in Fig. 7. Therefore, the controller controls the output current only when the PCS operates in GC mode. The relationship between the inverter output voltage and current is derived as 


$$
G_{1}(s)=\frac{i_{i}(s)}{v_{i}(s)}=\frac{1}{s L_{f}+R_{f}}
$$

where $G_{1}(s)$ is the current open-loop transfer function.

However, when the grid is disconnected (i.e., when grid fault occurs), the PCS operates in SA mode. In this mode, the PCS should operate as a voltage source to continuously supply power to the critical load. Hence, the PCS maintains the same load voltage as that when the grid is connected. The relationship between the inverter output voltage and the load voltage is derived as

$$
G_{2}(s)=\frac{v_{L}(s)}{v_{i}(s)}=\frac{1}{s C_{f}} / / Z_{\text {load }}
$$

where $Z_{\text {load }}=R_{L} / / s L_{L} / / \frac{1}{s C_{L}}$, and $G_{2}(\mathrm{~s})$ is the voltage open-loop transfer function.

When the load voltage is not equal to the grid voltage, the output value of feedforward control loop can affect the controller derived in Fig. 8. This output value of the feedforward control loop helps the controller rapidly adjust the load voltage. Compared with Fig. 6, feedforward control method has a simple calculating sequence. Hence, the current and voltage operating time is almost simultaneous.

Using the voltage feedforward control with the current control loop and the direct load current, load voltage is regulated quickly. The rapid regulation of voltage when abnormal grid situations is occurred, helps make seamless transfer to be controlled easily.

\section{EXPERIMENTAL RESULTS}

The results of the experiment on the proposed seamless transfer control algorithm, under each case of load condition, are herein presented.

The specifications of the experiment are presented in Table II. Switching frequency and sampling frequency in this system are $7.2 \mathrm{kHz}$ and $14.4 \mathrm{kHz}$, respectively. The inductance and capacitance of the LC filter are $2.2 \mathrm{mH}$ and $12 \mu \mathrm{F}$, respectively. Fig. 8 shows an experimental prototype of the proposed seamless transfer control algorithm.

A DC supply is used to establish a constant DC-link value. This supply is connected with the PCS. The 3-phase load, which acts as the critical load, is also connected to the PCS. Other devices for activities such as, monitoring the PCS, checking the experimental wave forms, etc., are also used in this experiment.

Each of the experimental result waveforms shows the inverter output current $\left(i_{i}\right)$, the load volate $\left(v_{L}\right)$, the load frequency $\left(f_{L}\right)$, the inverter side switch $\left(S_{i}\right)$, and the grid side switch $\left(S_{g}\right)$.

A low level of switch signals indicate that the switch is on (i.e, the switch is connected). Meanwhile, a high level of switch signals indicate that the switch is off (i.e., the switch is disconnected). When the grid condition is normal, which
TABLE II

EXPERIMENTAL PARAMETERS

\begin{tabular}{c|c}
\hline Parameters & Value \\
\hline \hline Grid Phase RMS Voltage $\left(\mathrm{V}_{\mathrm{g}}\right)$ & $110 \mathrm{~V}$ \\
\hline Grid Frequency $\left(\mathrm{f}_{\mathrm{g}}\right)$ & $60 \mathrm{~Hz}$ \\
\hline DC-link Voltage $\left(\mathrm{V}_{\mathrm{dc}}\right)$ & $380 \mathrm{~V}$ \\
\hline Switching Frequency $\left(\mathrm{f}_{\mathrm{sw}}\right)$ & $7.2 \mathrm{kHz}$ \\
\hline Sampling Frequency $\left(\mathrm{f}_{\mathrm{s}}\right)$ & $14.4 \mathrm{kHz}$ \\
\hline Filter Inductor $\left(\mathrm{L}_{\mathrm{f}}\right)$ & $2.2 \mathrm{mH}$ \\
\hline Filter Capacitor $\left(\mathrm{C}_{\mathrm{f}}\right)$ & $12 \mu \mathrm{F}$ \\
\hline
\end{tabular}

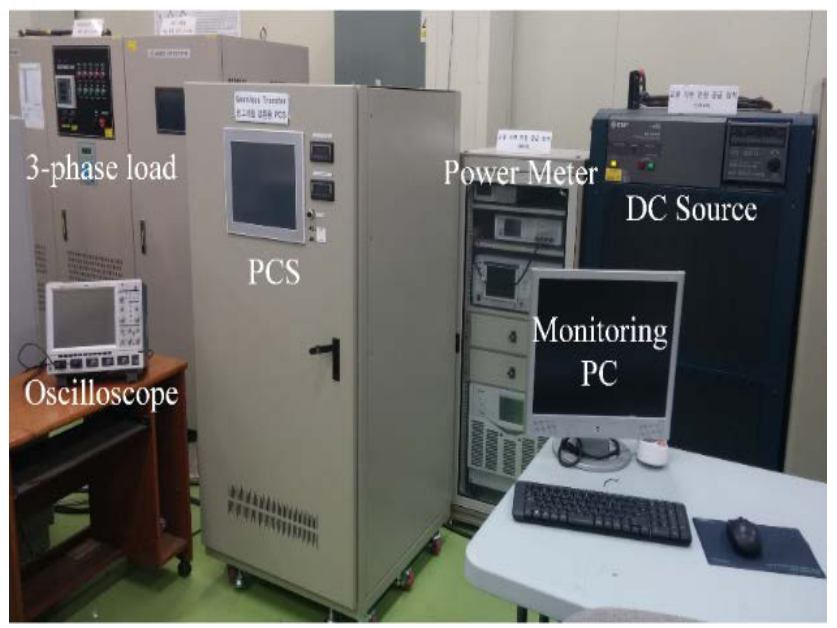

Fig. 9. Experimental setup of the proposed control algorithm.

means operation is in GC mode, the current is controlled well by the PCS output power reference and the load frequency operates near $60 \mathrm{~Hz}$ with small ripples. Meanwhile, when the grid condition is abnormal (i.e., the $S_{g}$ is open), the load frequency reaches the limit of the grid; after which, the PCS disconnects the $S_{i}$ from the grid side and changes its operation mode to maintain a load voltage equal to the GC-mode load voltage with a $60 \mathrm{~Hz}$-operation frequency. The experimental waveforms of the proposed seamless transfer control are shown in Figs. 10 and 11, respectively.

Fig. 10 shows the experimental waveform of the $5 \mathrm{~kW}$ output power of the PCS in GC mode. In Fig. 10(a), the PCS output power and load power are similar; hence, the load voltage and the PCS output current are changed minimally.

However, in Fig. 10(b), the PCS output power is much higher than the load power, and load voltage and the frequency change when the $S_{g}$ is disconnected instantly. The PCS also instantly disconnects the $S_{i}$ and changes operation modes.

Therefore, the load condition is recovered quickly and properly maintained at the same level as the GC-mode load voltage. The PCS output current is changed as well.

Fig. 11 shows the experimental results of the 50-VA PCS. Fig. 11(a) shows the low PCS output power under a high critical load condition. Much of the critical load power is supplied by the grid in GC mode. When the $S_{g}$ is opened instantly, the load voltage and the current change because of 


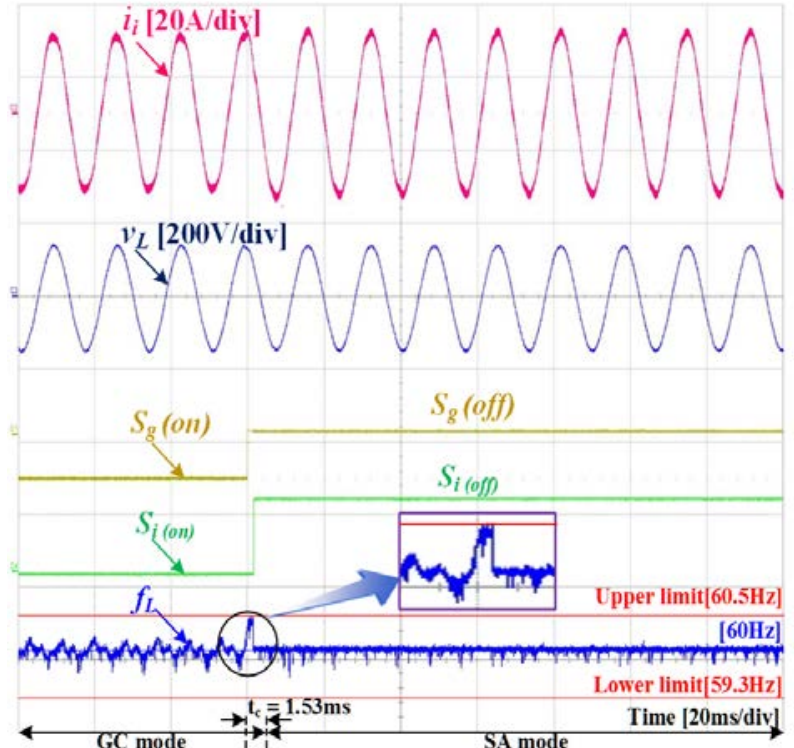

(a)

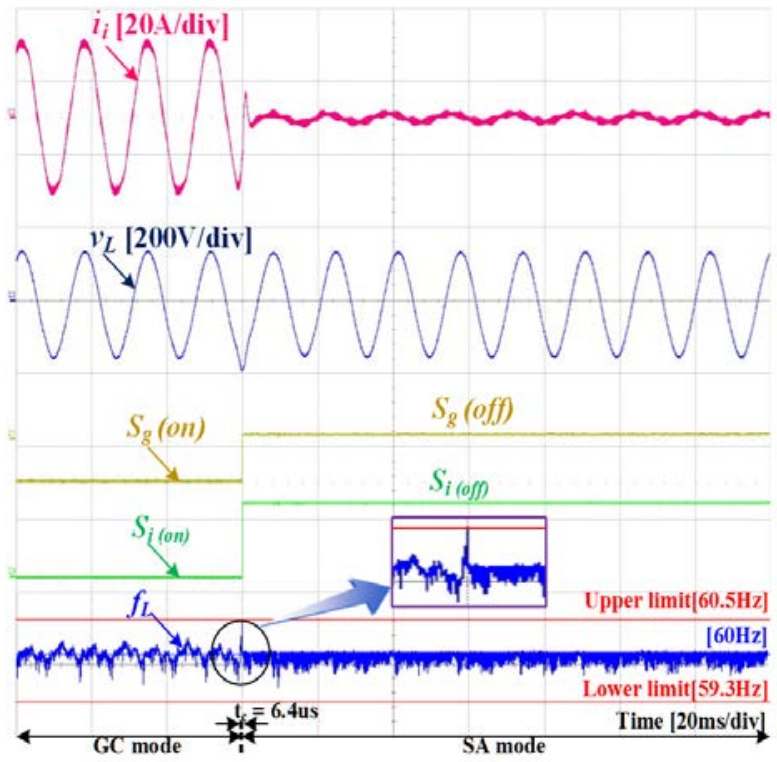

(b)

Fig. 10. Experimetal results of the proposed seamless transfer control algorithm from a $5 \mathrm{~kW}$-output power of the PCS in GC mode. (a) 5 kW resistive, 2 kVar inductive, capacitive load in SA mode. (b) $50 \mathrm{~W}$ resistive, 2 kVar inductive, capacitive load in SA mode.
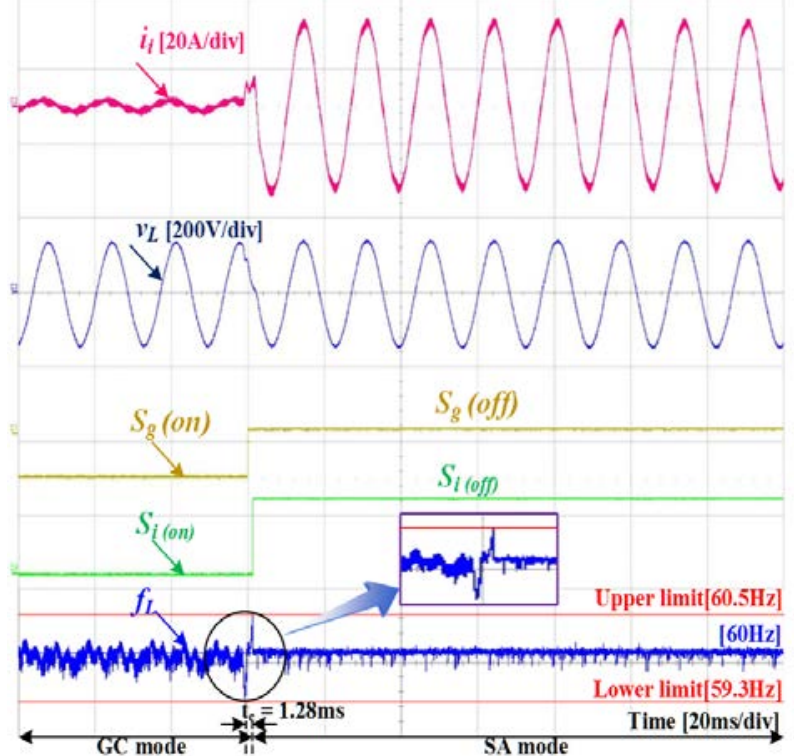

(a)

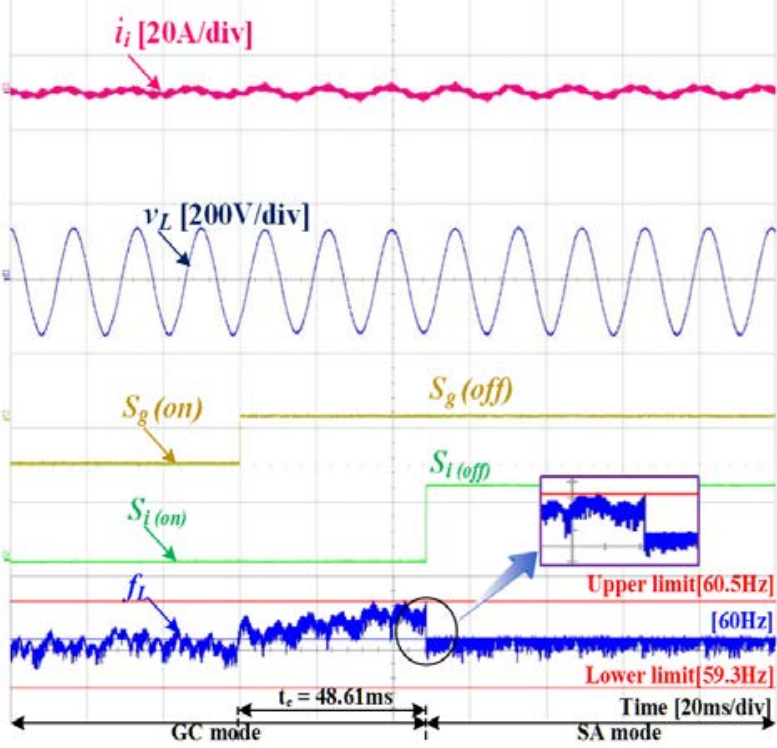

(b)

Fig. 11. Experimetal results of the proposed seamless transfer control algorithm from a $50 \mathrm{~W}$-output power of the PCS in GC mode. (a) 5 $\mathrm{kW}$ resistive, $2 \mathrm{kVar}$ inductive, capacitive load in SA mode. (b) $50 \mathrm{~W}$ resistive, $2 \mathrm{kVar}$ inductive, capacitive load in SA mode.

the significant power difference between the PCS and the critical load. After grid fault occurs, the PCS detects the abnormal condition and changes its operation mode as soon as possible to maintain the load voltage as if the grid were connected. Fig. 11(b) shows the low PCS output power under a light critical load condition. In this case, the tendency is similar to that in Fig. 10(a) (i.e., the power difference betweent the PCS and the load is small) except in terms of load frequency. As the PCS and the ciritical load power are small, detection time is longer than in other cases.

As Figs. 10(a) to 11(b) indicate, with a high PCS output power under a high or low critical load, and vice versa, the proposed seamless transfer control algorithm well-satisfies the clearing time specified in Table I in any of the conditions.

\section{CONCLUSION}

A seamless transfer control strategy based on the frequency detection method with a feedforward control is proposed in this paper. As the PCS checks grid conditions by continuously monitoring load voltage, the PCS can detect abnormal grid abnormal conditions as soon as possible. Furthermore, once the 
PCS recognizes the fault signal, the PCS changes its operation mode from GC to SA instantaneously. The current control with a feed-forward voltage loop controls the current according to the current reference in GC mode; this control helps quickly regulate the load voltage within the clearing time and maintains the load voltage, even under the light load conditions in SA mode. The experimental results demonstrate four cases of the relationship between the PCS and the critical load. The proposed seamless transfer control method is focused on critical loads such as emergency medical equipment. Therefore, the PCS senses the load current that needs to be controlled. Further study is needed to realize a general seamless transfer control.

The proposed control method is verified by the results of the experiment wherein PCS equipment is used.

\section{REFERENCES}

[1] J. P. Lee, B. D. Min, T. J. Kim, D. W. Yoo, J. Y. Yoo, “A novel topology for photovoltaic DC/DC full-bridge converter with flat efficiency under wide PV module voltage and load range," IEEE Trans. Indu. Electron., Vol. 55, No. 7, pp. 2655-2663, July 2008.

[2] Y. Hida, Y. Miyaguchi, R. Yokoyama, and K. Iba, “A study of optimal capacity of BESS to mitigate unstable of solar power generation," Modern Electric Power Systems (MEPS), 2010 Proceedings of the International Symposium, pp.1-5, Sep. 2010.

[3] X. Fang, S. Misra, G. Xue, and D. Yang, "Smart grid - The new and improved power grid: A survey," Commun. Surveys Tuts., Vol. 14, No. 4, pp. 944-980, Fourth Quarter 2012.

[4] IEEE Standard for Interconnecting Distributed Resources With Electric Power Systems, IEEE Standard 1547-2003, 2003.

[5] B. D. Min, J. P. Lee, J. H. Kim, T. J. Kim, D. W. Yoo, and E. H. Song "A new topology with high efficiency throughout all load range for photovoltaic PCS," IEEE Trans. Ind. Electron., Vol. 56, No. 11, pp. 4427-4435, Nov. 2009.

[6] H. Kim, T. Yu, and S. Choi, "Indirect current control algorithm for utility interactive inverters in distributed generation systems,” IEEE Trans. Power Electron., Vol. 23, No. 3, pp. 1342-1347, May 2008.

[7] J. Kwon, S. Yoon, and S. Choi, "Indirect current control for seamless transfer of three-phase utility interactive inverters," IEEE Trans. Power Electron., Vol. 27, No. 2, pp. 773-781, Feb. 2012.

[8] S. Yoon, H. Oh, and S. Choi, "Controller design and implementation of indirect current control based utility-interactive inverter system," IEEE Trans. Power Electron., Vol. 28, No. 1, pp. 26-30, Jan. 2013.

[9] Z. Liu and J. Liu, "Indirect current control based seamless transfer of three-phase inverter in distributed generation," IEEE Trans. Power Electron., Vol. 29, No. 7, pp. 3368-3383 Jul. 2014.

[10] Z. Liu, J. Liu, and Y. Zhao, "A unified control strategy for three-phase inverter in distributed generation," IEEE Trans. Power Electron., Vol. 29, No. 3, pp. 1176-1191, Mar. 2014.

[11] T. S. Hwang and S. Y. Park, "A seamless control strategy of a distributed generation inverter for the critical load safety under strict grid disturbances," IEEE Trans. Power Electron., Vol. 28, No. 10, pp. 4780-4790, Oct. 2013.

[12] J. P. Lee, B. D. Min, and D. W. Yoo, "Implementation of a high efficiency grid-tied multi-level photovoltaic power conditioning system using phase shifted H-bridge modules," Journal of Power Electronics, Vol. 13, No. 2, pp.296-303, Mar. 2013.

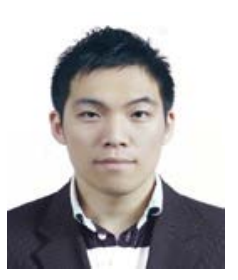

Kiryong Kim was born in Busan, Korea. He received his B.S. and M.S. degrees in electrical engineering in 2013 and 2015, respectively, from Pusan National University, Busan, Korea, from where he is also currently working toward a Ph.D. degree from the Department of Electrical Engineering. Since 2013, he has worked as a researcher with the Power Conversion Research Center, HVDC Research Division of Korea Electro-technology Research Institute, Changwon, Korea. His main research interests include control of grid-connected inverters and power quality.

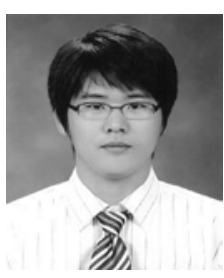

Dongsul Shin (S’13) received his B.S. and M.S. degrees in electrical engineering in 2009 and 2011, respectively, from Pusan National University, Busan, Korea, from where he is also currently working toward a Ph.D. degree from the Department of Electrical Engineering. Since 2010, he has worked as a researcher with the Power Conversion Research Center, HVDC Research Division Korea Electrotechnology Research Institute, Changwon, Korea. His main research interests include grid-connected inverters, power quality, and digital control.

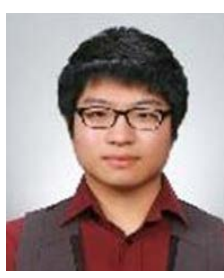

Jae-Cheol Lee was born in Changwon, Korea. He received his B.S. degree in electrical engineering from Pusan National University, Busan, Korea, in 2014. He is currently working toward a M.S degree from the Department of Electrical Engineering. His research interests include power converters and super capacitors for battery energy storage system.

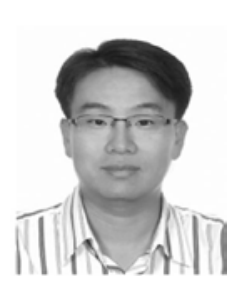

Jong-Pil Lee (M'13) received his B.S. and M.S. degrees in control and instrumentation of engineering in 1997, and in electrical engineering in 1999, respectively, from Korea University, Korea. He received his Ph.D. degree from the School of Electrical Engineering, Korea University, Korea in 2012. From 1999 to 2005, he was a senior researcher for the Electric and Hybrid Vehicle Research Department of Hyundai Heavy Industries. He has been working as a principal researcher at the Power Conversion Research Center for HVDC division of Korea Electro-technology Research Institute (KERI), Korea. His main research interests are photovoltaic PCS, PMSG wind-turbine PCS, distributed power generation systems, and power conversion for HVDC systems. 


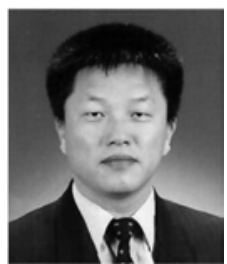

Dong-Wook Yoo (M’90) received his B.S. degree in electrical engineering from Sung-Kyun-Kwan University (SKKU), Suwon, Korea, in 1983. His M.S. degree in electrical engineering, he received from Yon-Sei University, Seoul, Korea, in 1985. He received his Ph. D. degree in power electronics from SKKU in 1997. Since 1985, he has been with Korea Electrotechnology Research Institute (KERI), Changwon, Korea, where he is currently an executive director of the HVDC Research Division. He is the author or coauthor of more than 30 publications in the IEEE Trans., and is the holder of more than 60 Korean patents and six U.S. patents. Dr. Yoo is a member of the IEEE PELS, IEEE IAS, Korean Institute of Power Electronics (KIPE), and Korean Institute of Electrical Engineers (KIEE). Since 1999, he has been a committee-member of KIPE. From 2009 to 2010, he was with the committee of KIEE, and from 2005 to 2006 and in 2009, he served as the chairman of the KIPE conference. He was also vice president of KIPE from 2010 to 2011. He was the co-recipient of the 2002 IEEE IECON Best Paper Award, the 2007 ICPE Best Paper Award, Daegu, Korea, the 2011 KIPE JPE Best Paper Award, and the 2013 KERI Grand Award.

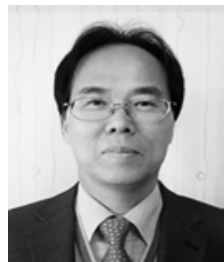

Hee-Je Kim received his B.S. and M.S. degrees in electrical engineering from Pusan National University, Busan, Korea, in 1980 and 1982, respectively. He received his Ph.D. degree from Kyushu University, Kyushu, Japan, in 1990. He joined the Korea Electrotechnology Research Institute in 1983 and was assigned to Kyushu University for a study on laser systems and plasma applications. Since 1995, he has worked as a professor at the Department of Electrical Engineering, Pusan National University. 